\title{
Study of Tibetan Students' Interpersonal Pragmatic Competence Model
}

\author{
Jing Yu \\ ABA Teachers University, Sichuan, China, 611730
}

Keywords: language socialization, pragmatic socialization, interlingual pragmatic competence, classroom instruction

Abstract: The theory of language socialization has been used by more and more researchers to analyze the pragmatics of second language acquisition from the perspective of social culture. It enables learners to achieve socialization through the learning of linguistic forms and enables learners to integrate into specific social cultures through expected roles and behaviors. The article analyzes the interlingual pragmatic competence of Tibetan Chinese learners from the perspective of pragmatic socialization, and concludes that under Tibetan-specific language learning environment, classroom education should be available as a social space for learners to use. Language and cultural knowledge enables students to use the correct and appropriate language to achieve the purpose of communication in cross-cultural communication.

\section{Introduction}

The use of language plays a very important role in social interpersonal communication. Language is not only a tool for exchanging information, but more importantly for realizing its social functions. Therefore, language is an important part of the process of human socialization. It allows learners to realize the process of socialization through the learning of linguistic forms and to accept corresponding values, behaviors, and social conventions so that language users can expect Roles and behaviors are integrated into specific social cultures. The study of language socialization believes that certain social, cultural and political environments will restrict the language forms that learners are exposed to, and at the same time it will also influence how learners use the language. In the society where language use and language communication are involved, pragmatics must be emphasized. Pragmatics is closely related to society. Therefore, a new topic in the study of language socialization is the pragmatic socialization.

\section{Pragmatic Socialization and Inter-lingual Pragmatic Competence}

Pragmatic socialization refers to how children learn to use language properly to complete communication tasks in a specific sociocultural context. In the process of mother tongue acquisition, learners must not only be exposed to linguistic rules, but also learn social and cultural information carried by the language. As an example of Tibetan students who use Chinese as a second language, pragmatic failures often occur in everyday cross-cultural communication, and communication fails. 
Because of the Chinese language as a foreign language, Tibetan L2 learners have difficulty accessing the culture of native Chinese, which leads to poor development of social pragmatic competence. Modern language teaching aims to develop the students' communicative competence. Therefore, the development of Tibetan students' interlingual pragmatic competence has become an important aspect that researchers and teachers are concerned about. However, the factors involved in the socialization of pragmatics in a cross-cultural context are complex. Chinese-speaking Tibetan-speaking Chinese learners who are native speakers of Chinese are more or less affected by their mother tongue when they are speaking in the second language. Some idioms such as idioms, vocabulary and syntactic structures in the mother tongue are inadvertently transferred to learners. In the use of the second language, it is easy for the learner to make a mistake or an indecent sentence. The impact of this mother tongue migration on Chinese learners can be expressed in many ways. This section mainly discusses the impact of pragmatic transfer on learners[1].

\section{Pragmatic migration}

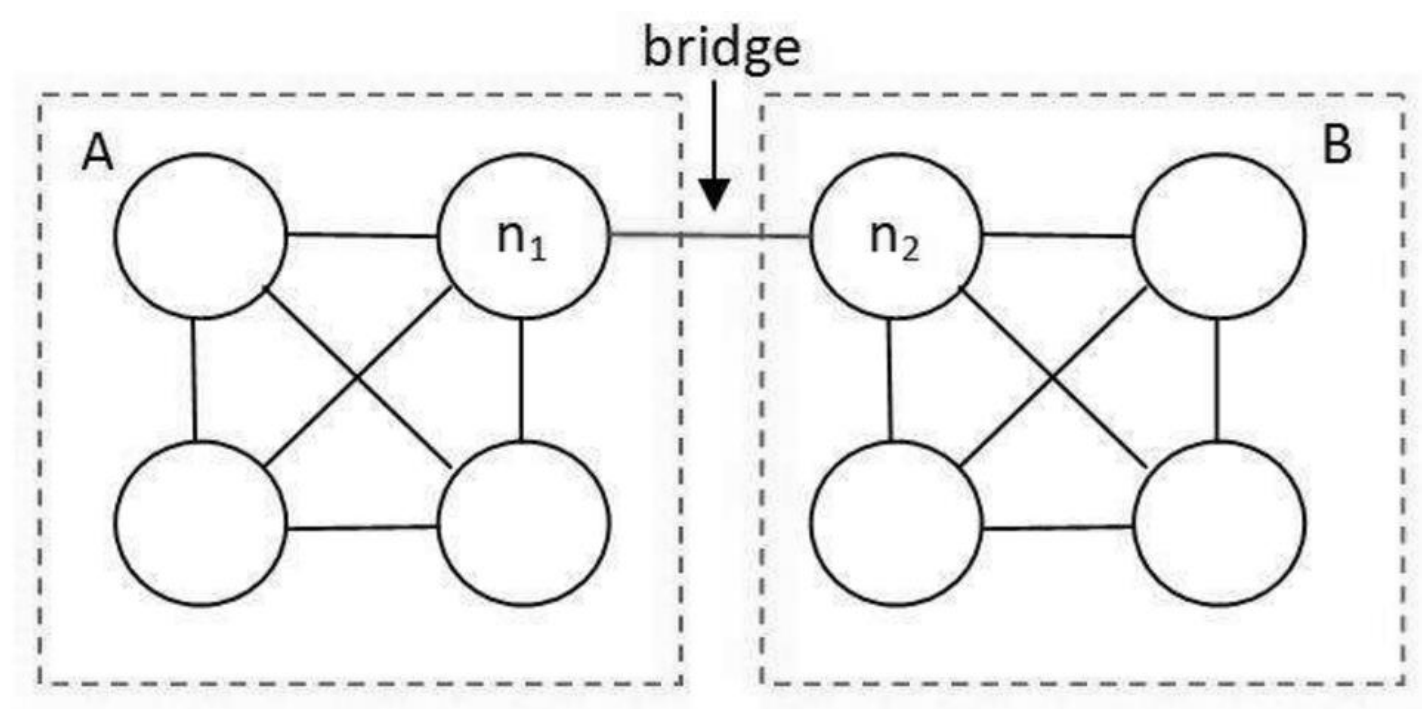

Fig.1 Pragmatic migration mode

Pragmatic transfer belongs to one aspect of cultural migration and it is an important feature of learners' interlingual language. It mainly studies the relationship between pragmatic language transfer and social pragmatic transfer, pragmatic failure and pragmatic competence. It is generally divided into two categories: pragmatic positive transfer and pragmatic negative transfer. Pragmatic positive transfer is that learners move the related linguistic knowledge in the mother tongue to the target language to express and understand the same verbal behavior. It is the pragmatic knowledge that the learner can easily grasp, and usually can guarantee the success of communication. The negative pragmatic transfer is that the learner moves a pragmatic knowledge in the mother tongue into the target language to express the same verbal behavior that the learner thinks is the same, but the pragmatic knowledge of the mother tongue is different from the existing understanding and expression of the target language. Caused a pragmatic mistake. Many researchers believe that social pragmatic failures are much more serious than pragmatic failures, because the former may be considered social etiquette and even moral issues of the speaker. For example, the same act of sending the elderly to cross the street will have a completely different reaction in Tibetan and the United States. It is a traditional virtue to respect the elderly in the cultural environment of Tibetans. Therefore, the old man will be praised for sending the elderly to cross the street, but in the United States, this The behavior may be understood as being detrimental to the personality, treating the old 
person as a person with disabilities who are incapable of moving, thus leading to the annoyance of the elderly. This cultural difference in face theory often leads Tibetan students to use the wrong language unconsciously[2]. Pragmatic migration mode is shown in the figure below.

\section{Application in Classroom Teaching}

Because Tibetan Chinese learners mainly use the classroom as the main mode of second language input, the role of teachers as facilitators in teaching should actively create a brand-new cultural experience for students, allowing students to accept other countries' unique features on the basis of understanding. Cultural conventions can help learners overcome cultural barriers in second language learning and promote the process of pragmatic socialization. This requires that Chinese teachers do not only teach basic language knowledge but also pragmatic analysis of language environment, language knowledge, and cultural background. In practical teaching, it is necessary not only to explicitly put forward the teaching goal of improving students' pragmatic competence, but also to implement this goal in all aspects of practical teaching[3]. Language training mode is as follows.

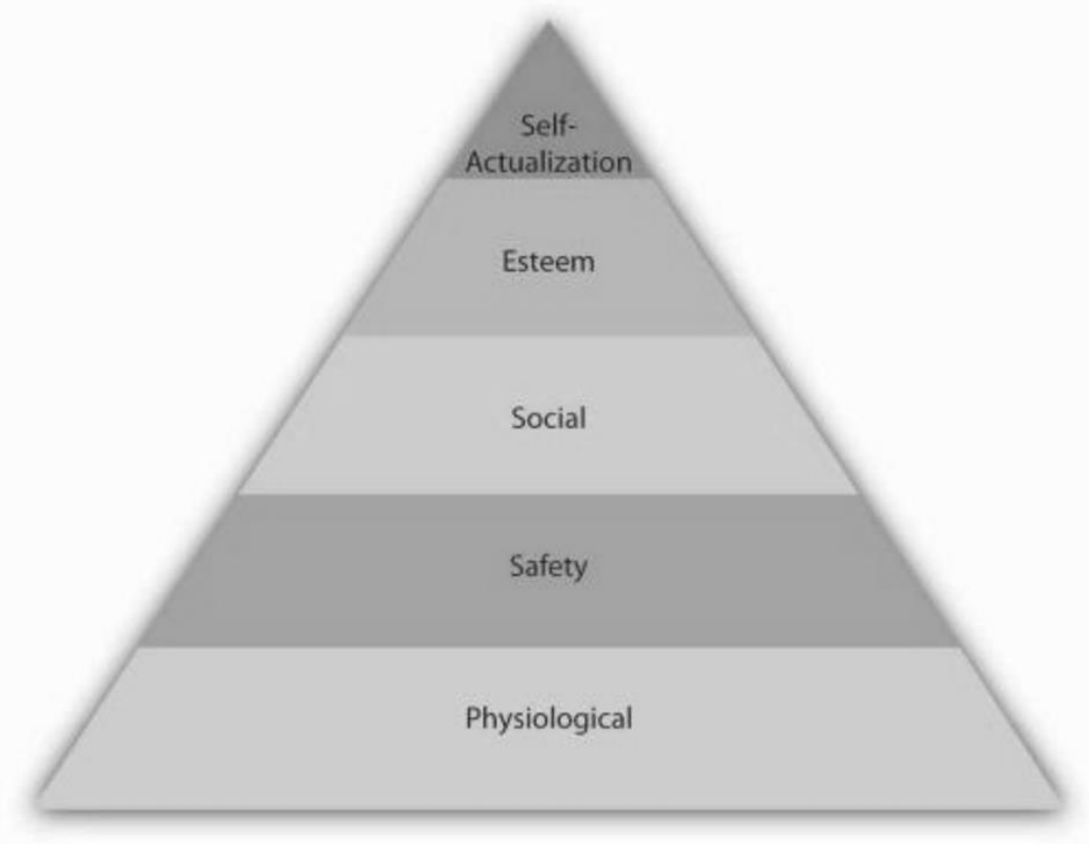

Fig.2 Language training mode

For example, in traditional Chinese teaching, grammar teaching occupies a large proportion, but the result is that it takes a lot of energy and the actual effect is poor. The result of this teaching method is that students have a good grammatical foundation, but they are full of errors in the real language communication environment. Either the students have achieved good grades for the exam and they have memorized grammar and rules. They can forget the grammar knowledge they have learned after the test. Students' grammatical and pragmatic competences become isolated and unbalanced development models. To guarantee the successful use and understanding of language, only the two are effectively combined. Therefore, the grammar teaching should combine the language form with language function, language rules and pragmatic rules to help students improve their ability to use language, and thus ensure the simultaneous development of grammar and pragmatic competence.

Because the application of pragmatic knowledge is closely related to the social factors and cultural factors of the context, the input of the language in accordance with the real social context 
will enable the learner to better grasp the pragmatic knowledge. In foreign language teaching, we can make full use of context and combine appropriate teaching content to improve students' pragmatic awareness. For example, when teaching speech expressions about refusal behavior, students can use role-playing methods to provide appropriate refusal speech expressions in various contexts; or let students find different language forms in listening activities to express The same pragmatic function.

Another issue that deserves our attention is that Chinese language learners learn this language in a foreign language environment. Therefore, textbooks have become the most direct tool for students to learn Chinese. The use of pragmatic principles as a criterion for consideration in the compilation of Chinese textbooks and teaching aids is also intended to improve students' awareness of cross-cultural communication and to include specific custom language forms, differences in Chinese and English speech behaviors, etc. as teaching materials. The focus also helps foreign language teachers attach importance to the teaching process[14].

\section{Summary}

The socialization of pragmatics in a cross-cultural context is a complex issue. The weak pragmatic competence affects the communication of Chinese learners. In order to improve the inter-lingual pragmatic competence, Chinese learners should pay more attention to the purpose in their daily learning life. The cultural features of the language recognize the cultural commonalities and characteristics of the two languages, eliminate and overcome the interference of the native language, and improve the efficiency of communication. Teachers' teaching in the classroom should also focus on the development of students' pragmatic competence. They should take care of students' pragmatic knowledge in the process of teaching language knowledge and base their efforts on cultivating language communicative competence including "grammar competence" and "pragmatic competence".

\section{Acknowledgement}

Aba Prefecture special fund project for Social Science in 2016: Research on the Interlanguage Pragmatic Competence and Its Development Model for the Minority Non-English Majors (ABK004)

This work in the project, On the Interlanguage Pragmatic Competence of Tibetan EFL Learners Based on Compliment Responses, was supported by the Scientific Research Foundation of Aba Teachers University in 2018 (No: ASB18-23).

\section{References}

[1] Miriam A. Locher. Interpersonal pragmatics and its link to (im)politeness research[J]. Journal of Pragmatics, 2015,86.

[2] Marcus J.H. Huibers, Gerard van Breukelen, Jeffrey Roelofs, Steven D. Hollon, John C. Markowitz, Jim van Os, Arnoud Arntz, Frenk Peeters. Predicting response to cognitive therapy and interpersonal therapy, with or without antidepressant medication, for major depression: A pragmatic trial in routine practice[J]. Journal of Affective Disorders, 2014,152-154.

[3] Livia Hartmann Souza, Giovanni Abrahão Salum, Bruno Paz Mosqueiro, Marco Antonio Caldieraro, Tadeu Assis Guerra, Marcelo P. Fleck. Interpersonal psychotherapy as add-on for treatment-resistant depression: A pragmatic randomized controlled trial[J]. Journal of Affective Disorders,2016,193.

[4] Donald G. Ellis, Mark Hamilton. Syntactic and pragmatic code usage in interpersonal communication[J]. Communication Monographs, 1985,52(3). 